Notes and miscellanea

\section{Lung mechanics in relation to radiographic category of coalworkers' simple pneumoconiosis}

We write to suggest that the conclusion in the paper by Legg, Cotes, and Bevan (February 1983) that non-bronchitic miners with categories " 2 and 3 " simple pneumoconiosis who have never smoked have lower pulmonary function values than those with categories " 0 and 1 " should be treated with some caution.

The epidemiological section of the MRC Pneumoconiosis Research Unit was very interested in this problem in the 1950 s when we were studying random samples of mining communities, and we have been able to find some results from these old surveys relevant to this problem. Unfortunately, we cannot present them all in the same form as in Legg's paper, as all the original data are no longer available, and our lung function testing was limited to the indirect maximum breathing capacity (IMBC).

The four groups are from random samples of miners and ex-miners aged 55-64 living in mining communities. The "non-smoker non-bronchitic" was defined by the MRC questionnaires. We have studied the populations carefully and are confident that we have included all the men with the relevant characteristics.

Table 1 shows the results in their original form. In table 2 we have calculated "\% predicted FEVs" for two of the groups, and in table 3 we have used Legg's unusual dichotomy "01-23" to make the comparison with his data more exact. The numbers unfortunately become very small, but we do not think any of the tables support Legg's results. Little

Table 1 Results in their original form

\begin{tabular}{|c|c|c|c|c|}
\hline \multirow[t]{2}{*}{ Area } & \multicolumn{2}{|c|}{ Category 0} & \multicolumn{2}{|c|}{ Categories 1,2,3 } \\
\hline & No & Mean/MBC & No & Mean/MBC \\
\hline $\begin{array}{l}\text { Rhondda Fach' } \\
\text { Leigh' } \\
\text { Staveley } \\
\text { Rhondda Fach } \\
\text { (unpublished) }\end{array}$ & $\begin{array}{r}2 \\
11 \\
14 \\
1\end{array}$ & $\begin{array}{l}82.0 \\
80.9 \\
99.9 \\
70.8\end{array}$ & $\begin{array}{l}5 \\
2 \\
4 \\
1\end{array}$ & $\begin{array}{r}94.2 \\
90.5 \\
102.3 \\
76.8\end{array}$ \\
\hline
\end{tabular}

Table 2 Results after calculations of "\% predicted FEVs" for two of the groups

\begin{tabular}{lrlll}
\hline Area & No & $\begin{array}{l}\text { Mean \% pred } \\
\text { FEV } \text { sec }\end{array}$ & No & $\begin{array}{l}\text { Mean \% pred } \\
F E V_{1} \text { sec }\end{array}$ \\
\hline Staveley & 14 & 98.8 & 4 & 107.0 \\
Rhondda & 1 & 72.8 & 1 & 70.3 \\
\hline
\end{tabular}

Table 3 Results after use of Legg's unusual dichotomy "01-23"

\begin{tabular}{lccll}
\hline Area & \multicolumn{2}{c}{ Categories 0 and 1} & & \multicolumn{2}{c}{ Categories 2 and 3} \\
\cline { 2 - 3 } \cline { 5 - 6 } & No & $\begin{array}{c}\text { Mean \% pred } \\
F E V, \text { sec }\end{array}$ & & $\begin{array}{l}\text { Mean \% pred } \\
F E V_{1} \text { sec }\end{array}$ \\
\hline $\begin{array}{l}\text { Staveley } \\
\text { Rhondda }\end{array}$ & 2 & $\begin{array}{c}100 \cdot 7 \\
70.6\end{array}$ & 2 & $100 \cdot 1$ \\
\hline
\end{tabular}

Corrected from original FEV 0.75 .

detail is given as to how Legg's cases were assembled but seemingly they were not obtained from random samples. Possibly there may have been some accidental bias introduced by their method of selection. For instance their odd comparison between categories " 0 and 1 " and " 2 and 3" may have led to a concealed comparison of cases referred by the pneumoconiosis panel with those discovered elsewhere.

\section{A L COCHRANE Rhoose Farm House, Rhoose. \\ F MOORE \\ 23 Wenvoe Terrace, Barry.}

\section{Legg, Cotes, and Bevan reply:}

We welcome Cochrane and Moore's scrutiny of this paper which was planned in the light of their finding made jointly with Higgins and others and subsequently confirmed by the National Coal Board that smoking and respiratory symptoms may affect the lung function of coalminers. To investigate patterns of abnormality associated with coal dust we studied lifetime non-smokers who were free from persistent cough and phlegm. Coalminers were recruited on account of their records being available from previous studies of working miners made by the pneumoconiosis unit $(n=4 / 6)$ and a random sample from the Rhondda Fach made by the epidemiological unit $(n=13 / 0)$; these were supplemented by approaches to the National Coal Board $(n=2 / 3)$ and Pneumoconiosis Medical Panel $(n=5 / 3)$ where the first and second numbers refer respectively to men in the $x$ ray categories 0,1 and 2,3 . This subdivi- 
sion was used to distinguish men without and with material quantities of lung dust. The groups were equally represented among the men from the several sources except for the epidemiological unit's random sample which, as might be expected, consisted predominantly of categories 0 and 1 . The men who were referred from the Pneumoconiosis Medical Panel had found their way there as a result of a National Coal Board periodic $x$-ray examination; they met the same selection criteria as the other subjects. Thus while the sampling procedure was not ideal it was not obviously biased in favour of the more disabled men being those with the higher categories of pneumoconiosis. In this our sample may have been better than that cited by Cochrane and Moore; their usable data came mainly from the
Staveley survey of which one of the conclusions was that men moved to those coal mines had above average respiratory health. A more definitive population might be drawn by the NCB but meanwhile our findings appear to be not unrepresentative: we hope that they will stimulate others to carry the subject further.

\section{References}

' Higgins ITT. Tobacco smoking, respiratory symptoms, and ventilatory capacity. Studies in random samples of the population. Br Med J 1959;i:325-9.

${ }^{2}$ Higgins ITT, Cochrane AL, Gilson JC, Wood CD. Population studies of chronic respiratory disease. A comparison of miners, foundryworkers, and others in Staveley, Derbyshire. Br J Ind Med 1959;16:255-68.

\section{Notice}

Royal College of Physicians of Ireland: Faculty of Occupational Medicine

Parts I and II of the examination for the membership of the faculty will be held in May and November each year. Details may be obtained from the Examination Office, Royal College of Physicians of Ireland, 6 Kildare Street, Dublin 2.

\section{Correction}

Fibre type and concentration in the lungs of workers in an asbestos cement factory (Nov 1983)

It has been brought to my attention that the interpretation which we made $(B r J$ Ind Med 1983:40;375-9) of results published by Newhouse and her colleagues ${ }^{1}$ was incorrect. In our paper we stated (in the first paragraph of the paper) that these authors found ten mesotheliomas in a cohort apparently exposed only to chrysotile. In fact, eight of the ten patients with mesothelioma in that study had had a definite exposure to crocidolite during one specific job.

B Gylseth, Institute of Occupational Health, Oslo 1, Norway.

' Newhouse ML, Berry G, Skidmore JW. A mortality study of workers manufacturing friction materials with chrysotile asbestos. Ann Occup Hyg 1982:26;899-909. 